\title{
Preparation and characterization of volatile alkaline-earth metal complexes with multiply coordinated aminoalkoxide ligands
}

\author{
Yun Chi, ${ }^{* a}$ Sudhir Ranjan, ${ }^{a}$ Tsung-Yi Chou, ${ }^{a}$ Chao-Shiuan Liu, ${ }^{* a}$ Shie-Ming Peng ${ }^{b}$ \\ and Gene-Hsiang Lee ${ }^{b}$ \\ a Department of Chemistry, National Tsing Hua University, Hsinchu 30013, Taiwan, \\ Republic of China. E-mail: ychi@mx.nthu.edu.tw \\ ${ }^{b}$ Department of Chemistry and Instrumentation Center, National Taiwan University, \\ Taipei 10764, Taiwan, Republic of China
}

\author{
Received 12th April 2001, Accepted 14th June 2001 \\ First published as an Advance Article on the web 9th August 2001
}

\begin{abstract}
The aminoalkoxide complexes $\mathrm{Sr}(\mathrm{amak})_{2}(\mathbf{1})$ and $\mathrm{Ba}(\mathrm{amak})_{2}(2)$ were prepared by treatment of a multiply-chelating fluorinated aminoalcohol ligand $\mathrm{HOC}\left(\mathrm{CF}_{3}\right)_{2} \mathrm{CH}_{2} \mathrm{~N}\left(\mathrm{CH}_{2} \mathrm{CH}_{2} \mathrm{OMe}\right)_{2}$, (amak)H, with the Group 2 metal reagents $\mathrm{Sr}\left(\mathrm{OPr}^{\mathrm{i}}\right)_{2}$ and $\mathrm{BaH}_{2}$ respectively. Single crystal X-ray diffraction studies indicate that complex 1 possesses an 8-coordinate distorted bicapped octahedral geometry with all $\mathrm{O}$ and $\mathrm{N}$ atoms coordinated to the central $\mathrm{Sr}$ cation. However, complex 2 adopts a unique 10-coordinate bicapped square antiprismatic structure, of which the coordination number is increased by two fluorine-to-barium dative interactions. Variable temperature ${ }^{19} \mathrm{~F}$ NMR studies show the existence of two inter-convertible isomers in solution and their possible molecular structures are proposed according to their structures in the solid-state. Preliminary investigation suggests that these complexes are good CVD source reagents for depositing $\mathrm{SrF}_{2}$ and $\mathrm{BaF}_{2}$ thin films.
\end{abstract}

There has been a growing interest in the use of Group 2 chemical vapor deposition (CVD) precursors for the preparation of a variety of metal oxide ${ }^{1}$ or metal fluoride thin films, ${ }^{2}$ the latter having potential application for manufacturing optical wave-guides or solid-state laser devices. ${ }^{3}$ Enhanced volatility and high thermal stability are the two most essential requirements for the better performance of such CVD precursors. As the fully saturated environment is expected to exhibit enhanced volatility by minimizing intermolecular attraction in the condensed phase, ${ }^{4}$ the challenge in finding new source reagents is thus centered on how to achieve coordinatively saturated metal centers. On the contrary, when the ligands of the complexes cannot provide a sufficient number of donor atoms, formation of multimetallic structures is expected; this situation has been demonstrated by the isolation of $\beta$-diketonate ${ }^{5}$ or alkoxide ${ }^{6}$ complexes such as $\left[\mathrm{Sr}_{3}(\mathrm{thd})_{6}\right]$ (thd = 2,2,6,6-tetramethylheptane-3,5-dionate), $\quad\left[\mathrm{Sr}_{3}(\mathrm{thd})_{6}\right.$ (Hthd)], $\left[\mathrm{Ba}(\mathrm{hfac})_{2}\left(\mathrm{H}_{2} \mathrm{O}\right)\right]_{n} \quad(\mathrm{hfac}=1,1,1,5,5,5$-hexafluoropentane-2,4-dionate), $\left[\mathrm{Ba}_{4}(\mathrm{thd})_{8}\right],\left[\mathrm{Ba}\left(\mathrm{O}^{\mathrm{t}} \mathrm{Bu}\right)_{2}\left(\mathrm{HO}^{t} \mathrm{Bu}\right)\right]_{4},\left[\mathrm{H}_{4}\right.$ $\left.\mathrm{Ba}_{6}\left(\mu_{6}-\mathrm{O}\right)\left(\mathrm{OC}_{2} \mathrm{H}_{4} \mathrm{OMe}\right)_{14}\right]$ and $\left[\mathrm{Ba}_{5}\left(\mu_{5}-\mathrm{OH}\right)\left\{\mathrm{OCH}\left(\mathrm{CF}_{3}\right)_{2}\right\}_{9^{-}}\right.$ $\left.(\mathrm{THF})_{4}\left(\mathrm{H}_{2} \mathrm{O}\right)\right]$. Most of these complexes are found to be thermally unstable or require a higher temperature for evaporation, making them less suitable for CVD experiments.

One successful method of achieving monomeric structures is to introduce a neutral ancillary ligand possessing a sufficient number of donor sites. For example, crown ether, glyme, ethanolamine and polyamine based chelate molecules have been utilized for stabilizing monomeric structures. ${ }^{7}$ Some representative examples involving volatile Group 2 metals include: $\quad \operatorname{Mg}(\text { thd })_{2}$ (tmeda) (tmeda $=$ tetramethylethylenediamine), $\mathrm{Sr}$ (thd $)_{2}$ (triglyme), $\mathrm{Ba}(\mathrm{hfac})_{2}(18$-crown-6) and $\mathrm{Ba}-$ $(\text { hfac })_{2}($ hmteta $) \quad(\text { hmteta }=\text { hexamethyltriethylenetetraamine })^{8}$ A second approach is to incorporate a chelating or a donor functionalized feature into the anionic ligand, so that it could satisfy the multiple coordination requirement of larger cations. This strategy has allowed the isolation of several volatile Group 2 metal complexes with oligoether substituted alcoholate ligands, ${ }^{10}$ or $\beta$-ketoiminate ligands involving a polyether appendage. ${ }^{11}$ The enhancement of volatility was attributed to a tendency of the polyether side chain to bind to the same metal atom in order to favor intramolecular chelation over intermolecular bonding.

In this paper, we wish to report the synthesis of two new monomeric Group 2 aminoalkoxide complexes $\mathrm{Sr}(\mathrm{amak})_{2}$ (1) and $\mathrm{Ba}(\text { amak })_{2}$ (2), (amak) $\mathrm{H}=\mathrm{HOC}\left(\mathrm{CF}_{3}\right)_{2} \mathrm{CH}_{2} \mathrm{~N}\left(\mathrm{CH}_{2} \mathrm{CH}_{2}-\right.$ $\mathrm{OMe})_{2}$. It is notable that the (amak)H ligand not only possesses an acidic hydroxyl group due to the presence of two electronwithdrawing $\mathrm{CF}_{3}$ groups, but also contains three additional donor atoms on the side chains that can provide desirable chelate interactions, forming a fully saturated coordination environment around the metal cation. Moreover, as the effective ionic radius of strontium $(1.40 \AA$ for coordination number $=8)$ differs greatly from that of barium $(1.66 \AA$ for coordination number $=10),{ }^{12}$ the structural identification of these two metal complexes would allow us to assess the bonding mode of ligands vs. the ionic radius of metal cations. Preliminary experiments were also carried out to evaluate their potential to serve as CVD source reagents for depositing $\mathrm{SrF}_{2}$ and $\mathrm{BaF}_{2}$ thin films, as these aminoalkoxide complexes were reasonably volatile.

\section{Experimental}

\section{General information and materials}

Mass spectra were obtained on a JEOL SX-102A instrument operating in electron impact (EI) mode. ${ }^{1} \mathrm{H},{ }^{13} \mathrm{C}$ and ${ }^{19} \mathrm{~F}$ NMR spectra were recorded on Varian Mercury-400 or INOVA-500 instruments; chemical shifts are quoted with respect to internal standard tetramethylsilane for ${ }^{1} \mathrm{H}$ and ${ }^{13} \mathrm{C} \mathrm{NMR}$ and $\mathrm{CFCl}_{3}$ for ${ }^{19} \mathrm{~F} \mathrm{NMR}$ data. $\mathrm{BaH}_{2}$ and $\mathrm{Sr}\left(\mathrm{OPr}^{\mathrm{i}}\right)_{2}$ were purchased from Strem Chemicals and used as received. All reactions were performed under a nitrogen atmosphere using deoxygenated solvents dried with an appropriate reagent. Elemental analyses were carried out at the NSC Regional Instrumentation Center at National Cheng Kung University, Tainan, Taiwan. 


\section{Synthesis of (amak)H}

To a reaction flask equipped with a dry ice condenser, anhydrous hexafluoroacetone $(13.3 \mathrm{~g}, 0.08 \mathrm{~mol})$ was slowly added into a diethyl ether solution of diazomethane (3.4 g, 0.08 mol) prepared from Diazald ${ }^{\circledR}$. The reaction mixture was then stirred for three hours to allow complete formation of the oxirane compound $\left(\mathrm{CF}_{3}\right)_{2} \mathrm{COCH}_{2}$. Then $11.7 \mathrm{~g}(0.088 \mathrm{~mol})$ of bis(2-methoxyethyl)amine was added dropwise over a period of 15 minutes and the reaction mixture was stirred at room temperature overnight. Finally, the reaction was quenched by the addition of water and washed with a saturated $\mathrm{NaHCO}_{3}$ solution $(2 \times 20 \mathrm{~mL})$ to remove excess amine. The organic layer was dried over anhydrous $\mathrm{MgSO}_{4}$, the diethyl ether evaporated in vacuo and the resultant oily liquid purified by vacuum distillation, giving $13.3 \mathrm{~g}(53 \%)$ of colorless liquid with bp $60{ }^{\circ} \mathrm{C}$ at 1.2 Torr. Selected spectral data: ${ }^{1} \mathrm{H}$ NMR $\left(400 \mathrm{MHz}, \mathrm{CDCl}_{3}\right.$, $295 \mathrm{~K}): \delta 6.54(\mathrm{~s}, \mathrm{br}, 1 \mathrm{H}, \mathrm{OH}), 3.42\left(\mathrm{t},{ }^{3} J_{\mathrm{HH}}=5.1 \mathrm{~Hz}, 4 \mathrm{H}\right.$ $\left.\mathrm{OCH}_{2}\right), 3.30(\mathrm{~s}, 6 \mathrm{H}, \mathrm{OMe}), 3.16\left(\mathrm{~s}, 2 \mathrm{H}, \mathrm{CH}_{2}\right), 2.88\left(\mathrm{t},{ }^{3} J_{\mathrm{HH}}=5.1\right.$ $\left.\mathrm{Hz}, 4 \mathrm{H}, \mathrm{NCH}_{2}\right) \cdot{ }^{13} \mathrm{C} \mathrm{NMR}\left(100 \mathrm{MHz}, \mathrm{CDCl}_{3}, 295 \mathrm{~K}\right): \delta 123.5$ $\left(\mathrm{q},{ }^{1} J_{\mathrm{CF}}=286.7 \mathrm{~Hz}, \mathrm{CF}_{3}\right), 73.2\left(\mathrm{sept},{ }^{2} J_{\mathrm{CF}}=28.1 \mathrm{~Hz}, C\left(\mathrm{CF}_{3}\right)_{2}\right)$, $70.0\left(\mathrm{OCH}_{2}\right), 58.7(\mathrm{OMe}), 54.5\left(\mathrm{CH}_{2}\right), 53.5\left(\mathrm{NCH}_{2}\right) .{ }^{19} \mathrm{~F} \mathrm{NMR}$ $\left(470 \mathrm{MHz}, \mathrm{CDCl}_{3}, 295 \mathrm{~K}\right): \delta-77.6(6 \mathrm{~F})$.

\section{Reaction of (amak)H with $\mathrm{Sr}\left(\mathrm{OPr}^{\mathrm{i}}\right)_{2}$}

Strontium isopropoxide $(0.512 \mathrm{~g}, 2.49 \mathrm{mmol})$ in THF $(15 \mathrm{~mL})$ was taken in a $100 \mathrm{~mL}$ flask equipped with a condenser. To this was added $1.56 \mathrm{~g}$ of (amak)H (4.98 mmol). Then $30 \mathrm{~mL}$ of THF was added and the solution was brought to reflux for 40 hours. The solution was filtered to remove any insoluble impurities and the filtrate evaporated to dryness, giving a white crystalline powder. Finally, the product was purified by recrystallization from dichloromethane-heptane, giving $1.3 \mathrm{~g}$ of $\operatorname{Sr}(\text { amak })_{2}(1,1.73 \mathrm{mmol}, 75 \%)$ as colorless crystalline material, $\mathrm{mp}=196^{\circ} \mathrm{C}$. Spectral data of 1 : MS (EI, $70 \mathrm{eV}, \mathrm{m} / \mathrm{e}^{+}$, $\mathrm{L}=\mathrm{C}_{10} \mathrm{H}_{16} \mathrm{~F}_{6} \mathrm{NO}_{3}$ ), observed (actual) \{relative abundance [assignment]: $818 \quad(819) \quad\{4.2\} \quad\left[\mathrm{SrL}_{2}+\mathrm{SrF}\right], \quad 712 \quad(712)$ $\{1.0\}\left[\mathrm{SrL}_{2}\right], 566(565)\{17.2\}\left[\mathrm{SrL}_{2}-\mathrm{C}_{7} \mathrm{H}_{16} \mathrm{O}_{2} \mathrm{~N}\right], 400(400)$ $\{42.7\}[\mathrm{SrL}], 330(331)\{37.8\}\left\{\left[\mathrm{SrL}-\mathrm{CF}_{3}\right], 268(268)\{6.9\}\right.$ $\left[\mathrm{L}-\mathrm{C}_{2} \mathrm{H}_{5} \mathrm{O}\right], 146(146)\{100\} \quad\left[\mathrm{C}_{7} \mathrm{H}_{16} \mathrm{O}_{2} \mathrm{~N}\right], 107$ (107) $\{7.2\}$ $[\mathrm{SrF}] .{ }^{1} \mathrm{H}$ NMR $\left(400 \mathrm{MHz}, \mathrm{C}_{6} \mathrm{D}_{6}\right): \delta 3.49(\mathrm{~s}, 6 \mathrm{H}, \mathrm{OMe}), 3.22(\mathrm{br}$ m, 4H, $\left.\mathrm{OCH}_{2}\right), 2.93\left(\mathrm{~s}, 2 \mathrm{H}, \mathrm{CH}_{2}\right), 2.44$ (br, m, 4H, $\left.\mathrm{NCH}_{2}\right) .{ }^{13} \mathrm{C}$ $\operatorname{NMR}\left(100 \mathrm{MHz}, \mathrm{C}_{6} \mathrm{D}_{6}\right): \delta 127.2\left(\mathrm{q},{ }^{1} J_{\mathrm{CF}}=291.0 \mathrm{~Hz}, \mathrm{CF}_{3}\right), 82.7$ $\left(\mathrm{sept},{ }^{2} J_{\mathrm{CF}}=25.2 \mathrm{~Hz},\left(\mathrm{CF}_{3}\right)_{2} \mathrm{C}\right), 69.1\left(\mathrm{OCH}_{3}\right), 59.1\left(\mathrm{OCH}_{2}\right), 56.8$ $\left(\mathrm{CH}_{2}\right), 54.4\left(\mathrm{NCH}_{2}\right) .{ }^{19} \mathrm{~F}$ NMR $\left(470 \mathrm{MHz}, \mathrm{CD}_{2} \mathrm{Cl}_{2}, 295 \mathrm{~K}\right)$ : $\delta-79.2(6 \mathrm{~F}) ;{ }^{19} \mathrm{~F}$ NMR $\left(470 \mathrm{MHz}, \mathrm{CD}_{2} \mathrm{Cl}_{2}, 193 \mathrm{~K}\right): \delta-78.8$ (broad), -79.5 (broad). Anal. Calcd for $\mathrm{C}_{20} \mathrm{H}_{32} \mathrm{~F}_{12} \mathrm{~N}_{2} \mathrm{O}_{6} \mathrm{Sr}$ : C, 33.73; H, 4.53; N, 3.93. Found: C, 33.75; H, 4.69; N, 3.93\%.

\section{Reaction of (amak)H with $\mathrm{BaH}_{2}$}

Barium hydride $(0.49 \mathrm{~g}, 3.53 \mathrm{mmol})$ was taken in a $100 \mathrm{~mL}$ flask equipped with a condenser. To this was added dropwise $2.1 \mathrm{~g}$ of (amak)H (6.43 mmol). The resulting mixture was first stirred at $40{ }^{\circ} \mathrm{C}$ for 4 hours until evolution of gas stopped. Then $50 \mathrm{~mL}$ of THF was added and the solution was brought to reflux for 12 hours. The excess of $\mathrm{BaH}_{2}$ was removed by filtration and the filtrate evaporated to dryness, giving a light yellow powder. Finally, the product was purified by recrystallization from hot toluene, giving $2.15 \mathrm{~g}$ of $\mathrm{Ba}(\operatorname{amak})_{2}(2,2.82 \mathrm{mmol}, 84 \%)$ as colorless crystalline material, $\mathrm{mp}=155^{\circ} \mathrm{C}$. Spectral data of $\mathbf{2}$ : MS (EI, $70 \mathrm{eV}, m / e^{+}, \mathrm{L}=\mathrm{C}_{10} \mathrm{H}_{16} \mathrm{~F}_{6} \mathrm{NO}_{3}$ ), observed (actual) \{relative abundance\} [assignment]: 918 (919) $\{2.3\}\left[\mathrm{BaL}_{2}+\right.$ $\mathrm{BaF}], 762(762)\{1.1\} \quad\left[\mathrm{BaL}_{2}\right], 615$ (616) $\{11.9\} \quad\left[\mathrm{BaL}_{2}-\right.$ $\left.\mathrm{C}_{7} \mathrm{H}_{16} \mathrm{O}_{2} \mathrm{~N}\right], \quad 450 \quad(450) \quad\{61.3\} \quad[\mathrm{BaL}], \quad 380 \quad(381) \quad\{23.2\}$

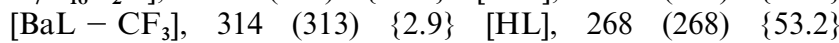
$\left[\mathrm{L}-\mathrm{C}_{2} \mathrm{H}_{5} \mathrm{O}\right], 157$ (157) $\quad \begin{array}{llllll} & 15.1\} & {[\mathrm{BaF}],} & 146 & (146) & \{100\}\end{array}$ $\left[\mathrm{C}_{7} \mathrm{H}_{16} \mathrm{O}_{2} \mathrm{~N}\right] .{ }^{1} \mathrm{H}$ NMR $\left(400 \mathrm{MHz}, \mathrm{CD}_{3} \mathrm{CN}\right): \delta 3.65(\mathrm{t}, 4 \mathrm{H}$, $\left.{ }^{3} J_{\mathrm{HH}}=4.9 \mathrm{~Hz}, \mathrm{OCH}_{2}\right), 3.51(\mathrm{~s}, 6 \mathrm{H}, \mathrm{OMe}), 2.80\left(\mathrm{~s}, 2 \mathrm{H}, \mathrm{CH}_{2}\right)$, $2.77\left(\mathrm{t}, 4 \mathrm{H},{ }^{3} \mathrm{~J}_{\mathrm{HH}}=4.9 \mathrm{~Hz}, \mathrm{NCH}_{2}\right) .{ }^{13} \mathrm{C} \mathrm{NMR}(100 \mathrm{MHz}$,
Table 1 X-Ray structural data for complexes 1 and 2

\begin{tabular}{lll}
\hline & $\mathbf{1}$ & $\mathbf{2}$ \\
\hline Formula & $\mathrm{C}_{22} \mathrm{H}_{36} \mathrm{Cl}_{4} \mathrm{~F}_{12} \mathrm{~N}_{2} \mathrm{O}_{6} \mathrm{Sr}$ & $\mathrm{C}_{20} \mathrm{H}_{32} \mathrm{BaF}_{12} \mathrm{~N}_{2} \mathrm{O}_{6}$ \\
$M$ & 881.95 & 761.82 \\
$T / \mathrm{K}$ & 150 & 295 \\
Crystal system & Monoclinic & Monoclinic \\
Space group & $P 2 / n$ & $P 2_{1} / n$ \\
$a / \AA$ & $9.2804(2)$ & $10.048(3)$ \\
$b / \AA$ & $11.4196(3)$ & $14.977(3)$ \\
$c / \AA$ & $16.8509(4)$ & $21.031(4)$ \\
$\beta / /^{\circ}$ & $104.152(1)$ & $94.48(3)$ \\
$V / \AA^{3}$ & $1731.63(7)$ & $3005.4(12)$ \\
$Z$ & 2 & 4 \\
$D_{\mathrm{c}} / \mathrm{g}$ cm & \\
$\mu(\mathrm{Mo}-\mathrm{K} \alpha) / \mathrm{mm}^{-1}$ & 1.691 & 1.684 \\
No. of data in refinement & 1.968 & 1.431 \\
No. of parameters & 3934 & 5288 \\
$R_{1}$, w $R_{2}$ with $I>2 \sigma(I)$ & 215 & 371 \\
\hline
\end{tabular}

$\left.\mathrm{CD}_{3} \mathrm{CN}\right): \delta 126.9\left(\mathrm{q},{ }^{1} J_{\mathrm{CF}}=293.0 \mathrm{~Hz}, \mathrm{CF}_{3}\right), 82.4$ (sept, $\left.{ }^{2} J_{\mathrm{CF}}=25.0 \mathrm{~Hz},\left(\mathrm{CF}_{3}\right)_{2} \mathrm{C}\right), 69.7\left(\mathrm{OCH}_{2}\right), 58.4\left(\mathrm{OCH}_{3}\right), 56.7$ $\left(\mathrm{CH}_{2}\right), 54.6\left(\mathrm{NCH}_{2}\right) .{ }^{19} \mathrm{~F} \mathrm{NMR}\left(470 \mathrm{MHz}, \mathrm{CD}_{2} \mathrm{Cl}_{2}, 295 \mathrm{~K}\right)$ : $\delta-78.9(6 \mathrm{~F}) ;{ }^{19} \mathrm{~F}$ NMR (470 MHz, $\left.\mathrm{CD}_{2} \mathrm{Cl}_{2}, 193 \mathrm{~K}\right): \delta-78.2$ (very broad), -79.2 (broad). Anal. Calcd for $\mathrm{C}_{20} \mathrm{H}_{32} \mathrm{~F}_{12} \mathrm{~N}_{2} \mathrm{O}_{6} \mathrm{Ba}$ : $\mathrm{C}, 31.53 ; \mathrm{H}, 4.23 ; \mathrm{N}, 3.68$. Found: $\mathrm{C}, 31.51 ; \mathrm{H}, 4.46 ; \mathrm{N}$, $3.52 \%$.

\section{CVD experiments}

The thermal CVD reactions were carried out using a horizontal hot-wall reactor, consisting of a Pyrex tube of $25 \mathrm{~mm}$ internal diameter, placed within an electric temperature-controlled tube furnace. The precursors were loaded in a glass container, which served as precursor reservoir and attached at the far end of the Pyrex tube. The temperature of the sample reservoir was adjusted to $180-200^{\circ} \mathrm{C}$. The carrier gas was introduced through the sidearm of the container, which became saturated with the vapor of the source reagent and then entered the hot zone, where deposition took place. The flow rate of the carrier gas was typically adjusted to $\approx 30 \mathrm{~mL} \mathrm{~min}{ }^{-1}$. The deposition temperature was kept at $300-400{ }^{\circ} \mathrm{C}$, and the deposition time set typically between 20 and $40 \mathrm{~min}$. The $\mathrm{Si}$ substrates were cleaned using dilute HF solution, then washed with de-ionized water and acetone.

\section{X-Ray crystallography}

X-Ray diffraction data of complex 1 was measured on a Bruker SMART CCD diffractometer using $\lambda(\mathrm{Mo}-\mathrm{K} \alpha)$ radiation $(0.7107 \AA)$. The crystallographic data were collected over a hemisphere of reciprocal space, by a combination of three sets of exposures. Each set had a different $\varphi$ angle for the crystal and each exposure of 10 seconds covered $0.30^{\circ}$ in $\omega$. The data collection was executed using the SMART program. ${ }^{13}$ An empirical absorption was based on symmetry-equivalent reflections and applied to the data using the SADABS program. ${ }^{13}$ The structure was solved using the SHELXTL-97 program. ${ }^{13}$ For complex 2, the crystallographic data were collected on a Nonius CAD-4 diffractometer. Initial lattice parameters were determined from 25 accurately centered reflections with $2 \theta$ values in the range 18.86 to $30.22^{\circ}$. Reflection data were collected using the $\theta / 2 \theta$ scan mode. The $\theta$ scan angle was then determined for each reflection according to the expression $0.65+0.35 \tan \theta$. A semi-empirical absorption correction from psi-scans was applied.

Finally, anisotropic thermal parameters were used for all non-hydrogen atoms, while the hydrogen atoms were given fixed isotropic displacement parameters. The crystallographic refinement parameters of complexes $\mathbf{1}$ and $\mathbf{2}$ are summarized in Table 1.

CCDC reference numbers 163031 and 163032. 
See http://www.rsc.org/suppdata/dt/b1/b103310g/ for crystallographic data in CIF or other electronic format.

\section{Results and discussion}

The fluorinated aminoalcohol ligand (amak)H was prepared in good yield by direct treatment of the amine $\mathrm{HN}\left(\mathrm{CH}_{2}-\right.$ $\left.\mathrm{CH}_{2} \mathrm{OMe}\right)_{2}$ and the fluorinated oxirane $\left(\mathrm{CF}_{3}\right)_{2} \mathrm{COCH}_{2}$ in diethyl ether solution, the latter is generated in-situ from hexafluoroacetone and diazomethane etherate at ambient temperature. ${ }^{14}$ This aminoalcohol (amak)H is the first fluorinated alcoholate ligand with a donor-functionalized side chain, ${ }^{6,9}$ where its parent fluoroalkoxide ligands formed stable metal complexes with approximate formula $\left[\mathrm{Ba}\left(\mathrm{OR}_{\mathrm{F}}\right)_{2}\right], \mathrm{R}_{\mathrm{F}}=\mathrm{CH}\left(\mathrm{CF}_{3}\right)_{2}$ and $\mathrm{CMe}\left(\mathrm{CF}_{3}\right)_{2}$, but their crystal structures were not determined. ${ }^{15}$ On the contrary, the related aminoalkoxide ligands have recently been applied to synthesize the volatile $\mathrm{Cu}$ (II) complexes $\left[\mathrm{Cu}\left\{\mathrm{OC}\left(\mathrm{CF}_{3}\right)_{2} \mathrm{CH}_{2} \mathrm{NHR}\right\}_{2}\right], \mathrm{R}=\mathrm{Me}, \mathrm{CH}_{2} \mathrm{CH}_{2} \mathrm{OMe}, \mathrm{Bu}^{\mathrm{i}}$, for generation of copper metal thin films using chemical vapor deposition. $^{16}$

As indicated in Scheme 1, synthesis of the strontium amino-<smiles>COCCN(CCOC)CC(O)(F)C(F)(F)F</smiles>

(amak)H

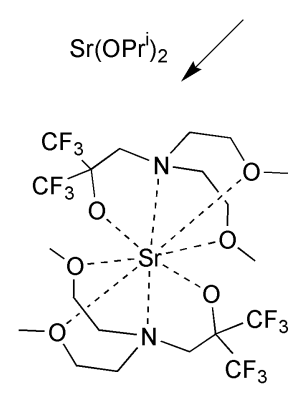

(1)

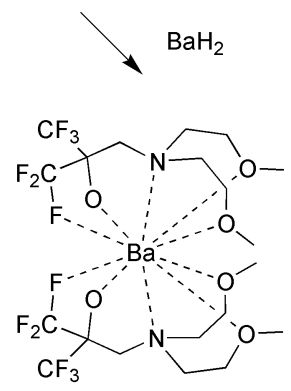

(2)
Scheme 1

alkoxide complex $\operatorname{Sr}(\operatorname{amak})_{2}$ (1) was achieved by treatment of the isopropoxide complex $\mathrm{Sr}\left(\mathrm{OPr}^{\mathrm{i}}\right)_{2}$. The related barium complex $\mathrm{Ba}(\mathrm{amak})_{2}(2,84 \%)$ was prepared using $\mathrm{BaH}_{2}$ as the source reagent. Both complexes are found to be sparingly soluble in non-polar hydrocarbons such as hexane and cold toluene but are much more soluble in solvents such as $\mathrm{CHCl}_{3}$, $\mathrm{CH}_{2} \mathrm{Cl}_{2}$ and THF. Finally, as both alkoxide complexes are found to be moderately sensitive to moisture upon exposure to air, storage under an inert atmosphere is needed.

The identity of these two complexes was initially revealed by EI mass analysis, of which the parent molecular ions $\mathrm{M}^{+}$, along with the fragmentation ions were clearly observed, showing formation of the expected molecular formula. A subsequent single crystal X-ray diffraction study indicates that complex $\mathbf{1}$ contains one monomeric metal entity and two uncoordinated $\mathrm{CH}_{2} \mathrm{Cl}_{2}$ solvates in the asymmetric unit. The strontium atom is situated on a crystallographic center of inversion and bonded to all four heteroatoms of the amak ligand, giving a tetradentate chelate interaction encircling the central metal atom (Fig. 1). The $\mathrm{Sr}-\mathrm{O}(3)$ distance (2.436(2) Å) is found to be much shorter than the respective $\mathrm{Sr}-\mathrm{O}($ ether) dative interactions, $\mathrm{Sr}-\mathrm{O}(1)(2.605(2))$ and $\mathrm{Sr}-\mathrm{O}(2)(2.671(2) \AA)$, which shows the presence of the stronger bonding interaction between the $\mathrm{Sr}^{2+}$ cation and the $(-1)$ negatively charged $\mathrm{O}(3)$ atom. As these six oxygen donor atoms constitute a slightly distorted octahedral skeletal arrangement, the immediate coordination geometry of $\mathbf{1}$ is best described as bicapped octahedron, where the two capping atoms are the $\mathrm{N}(1)$ and $\mathrm{N}(1 \mathrm{~A})$ atoms, located at the

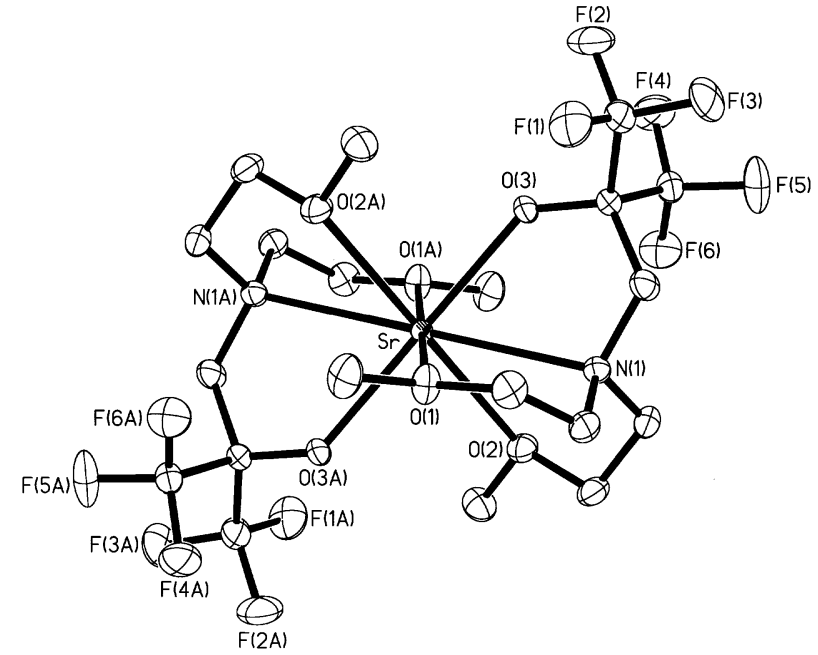

Fig. 1 ORTEP ${ }^{13}$ drawing of 1 with thermal ellipsoids shown at the $50 \%$ probability level. Selected bond lengths $(\AA)$ : $\mathrm{Sr}-\mathrm{O}(1)=2.605(2)$, $\mathrm{Sr}-\mathrm{O}(2)=2.671(2), \mathrm{Sr}-\mathrm{O}(3)=2.436(2)$ and $\mathrm{Sr}-\mathrm{N}(1)=2.933(2)$.

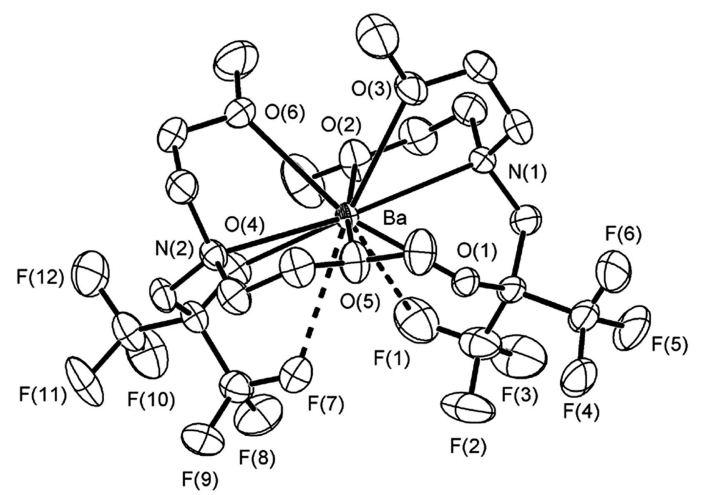

Fig. 2 ORTEP ${ }^{13}$ drawing of 2 with thermal ellipsoids shown at the $30 \%$ probability level. Selected bond lengths $(\AA): \mathrm{Ba}-\mathrm{O}(1)=2.562(2)$, $\mathrm{Ba}-\mathrm{O}(2)=2.878(3), \mathrm{Ba}-\mathrm{O}(3)=2.862(3), \mathrm{Ba}-\mathrm{O}(4)=2.558(2), \mathrm{Ba}-\mathrm{O}(5)=$ $2.820(3), \mathrm{Ba}-\mathrm{O}(6)=2.832(3), \mathrm{Ba}-\mathrm{N}(1)=3.003(3), \mathrm{Ba}-\mathrm{N}(2)=3.080(3)$, $\mathrm{Ba}-\mathrm{F}(1)=3.212(3)$ and $\mathrm{Ba}-\mathrm{F}(7)=3.132(2)$. Bond angle $\left({ }^{\circ}\right)$ : $\mathrm{N}(1)-\mathrm{Ba}-$ $\mathrm{N}(2)=169.50(8)$.

center of the triangular faces defined by the $\mathrm{O}(1), \mathrm{O}(2)$ and $\mathrm{O}(3)$ and the $\mathrm{O}(1 \mathrm{~A}), \mathrm{O}(2 \mathrm{~A})$ and $\mathrm{O}(3 \mathrm{~A})$ atoms. Moreover, the $\mathrm{Sr}-$ $\mathrm{N}$ (1) distance of 2.933(2) $\AA$ is found to be much longer with respect to the $\mathrm{Sr}-\mathrm{O}$ (ether) distances discussed earlier (2.605(2)2.671(2) $\AA$ ). Since this difference in bond distance $(\approx 0.3 \AA)$ is greater than the difference between the radius of the nitrogen and oxygen atom $(0.02-0.05 \AA)$, our observation clearly indicates that lengthening of the $\mathrm{Sr}-\mathrm{N}$ distance is not due to the larger radius of the nitrogen atom, but due to the unfavorable angle strain imposed by three adjacent $\mathrm{C}-\mathrm{C}-\mathrm{N}$ linkages which prevents the nitrogen donor atom from getting too close to the central strontium cation.

In contrast, the barium complex 2 shows a 10-coordinate environment, of which the donor ligands consist of all available oxygen and nitrogen atoms and most importantly, two additional fluorine-to-barium contacts from the trifluoromethyl groups of the aminoalkoxide ligands (Fig. 2). Formation of $\mathrm{Ba} \cdot \mathrm{F}$. dative interactions with distances 2.87-3.29 $\AA$ have been cited in many literature reports. ${ }^{17}$ Such $\mathrm{Ba} \cdots \mathrm{F}$ contacts are observed in complex 2 with $\mathrm{Ba}-\mathrm{F}(1)=3.212(3) \AA$ and $\mathrm{Ba}-\mathrm{F}(7)=3.132(2) \AA$, both non-bonding distances of which are much shorter than the shortest $\mathrm{Sr} \cdots \mathrm{F}$ distance observed in complex $1(\mathrm{Sr} \cdots \mathrm{F}(6)=4.218 \AA)$ or the sum of the fluorine van der Waals' radius $(1.5 \AA)$ and the ionic radius of barium (1.66 $\AA) .{ }^{5 a}$ As a result, the coordination environment is best considered as a distorted bicapped square antiprism, resembling that observed in some other 10 -coordinate barium complexes. ${ }^{18}$ 


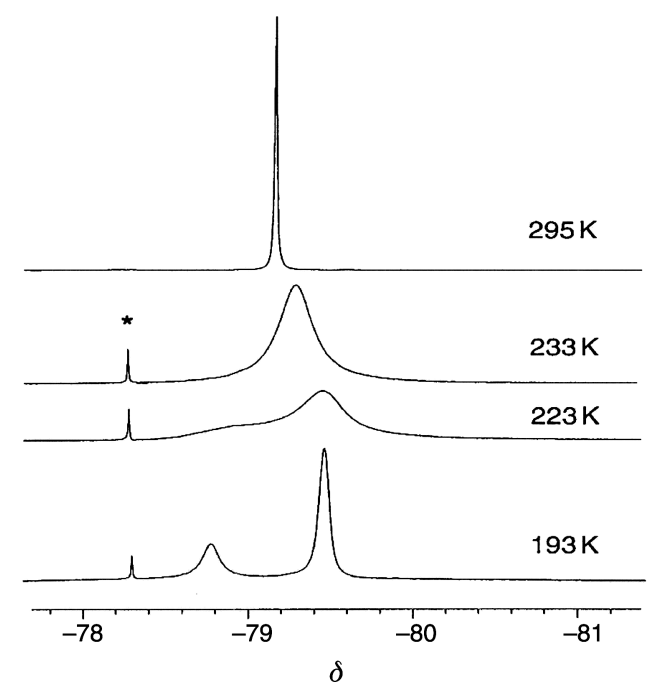

Fig. 3 VT ${ }^{19} \mathrm{~F}$ NMR spectra of $\mathbf{1}$ in $\mathrm{CD}_{2} \mathrm{Cl}_{2}$ solution; the signal marked with an asterisk is due to a small amount of free aminoalcohol.

The unique capping atoms in $\mathbf{2}$ are the nitrogen atoms $\mathrm{N}(1)$ and $\mathrm{N}(2)$, while the two square faces of the antiprism are defined by the atoms $\mathrm{O}(1), \mathrm{O}(3), \mathrm{O}(2)$ and $\mathrm{F}(1)$ and by the atoms $\mathrm{O}(4)$ $\mathrm{O}(6), \mathrm{O}(5)$ and $\mathrm{F}(7)$ respectively. In addition, the alkoxy termin of 2 are arranged in a bent position with an angle $\mathrm{O}(1)-\mathrm{Ba}-$ $\mathrm{O}(4)=124.4^{\circ}$. This geometry is in sharp contrast to that of complex $\mathbf{1}$, in which the alkoxy termini are located at the trans positions of the bicapped octahedral geometry.

The ${ }^{1} \mathrm{H}$ and ${ }^{13} \mathrm{C}$ NMR spectra at room temperature have been measured and all data are consistent with the proposed molecular structures. The variable temperature ${ }^{19} \mathrm{~F}$ NMR studies were next examined, and of particular interest is the ${ }^{19} \mathrm{~F}$ NMR spectrum of the barium complex 2 , which showed one sharp signal at $\delta-78.9$ at $295 \mathrm{~K}$ in $\mathrm{CD}_{2} \mathrm{Cl}_{2}$ solution. This signal begins to broaden upon lowering the temperature to $213 \mathrm{~K}$, and splits into two very broad signals centered at $\delta-78.2$ and -79.2 at $193 \mathrm{~K}$. The ${ }^{1} \mathrm{H}$ NMR spectrum recorded at this temperature is not well resolved, but it is basically consistent with the ${ }^{19} \mathrm{~F}$ NMR data. Moreover, a similar fluxional behavior is observed for the strontium complex 1 , showing only one sharp ${ }^{19} \mathrm{~F}$ NMR signal at $\delta-79.2$ in $\mathrm{CD}_{2} \mathrm{Cl}_{2}$ at $295 \mathrm{~K}$, and a broad peak upon lowering to $233 \mathrm{~K}$ which further turned into two sharp ${ }^{19} \mathrm{~F}$ NMR signals at $\delta-78.8$ and -79.5 with an approximate ratio of $1: 4$ at $193 \mathrm{~K}$ (Fig. 3). The large difference in the signal intensities indicated that they were not derived from the nonequivalent $\mathrm{CF}_{3}$ groups of the ligands in one single complex; therefore, the co-existence of two inter-convertible isomers was proposed.

Based on these VT ${ }^{19} \mathrm{~F}$ NMR experiments and the X-ray crystal structure established, the observed temperature-dependent behavior may be interpreted as a cis-to-trans isomerization of the coordinated aminoalkoxide ligands, giving co-existence of both cis-and trans-isomers of the bicapped octahedral complex $\mathbf{1}$ and the bicapped square antiprismatic complex $\mathbf{2}$, which are labeled as the $\mathbf{1}$ and $\mathbf{1}^{\prime \prime}$ pair and the $\mathbf{2}$ and $\mathbf{2}^{\prime \prime}$ pair in Scheme 2. This hypothesis is valid only if we assume that both complexes retain their monomeric nature and that the coordination number of each metal complex is preserved in solution, i.e. 8coordination for $\mathbf{1}$ and 10-coordination for $\mathbf{2}$, respectively. However, if we arbitrarily assume that the 10-coordinate cisgeometry is associated with the simultaneous presence of the $\mathrm{M} \cdots \mathrm{F}$ dative interactions, this would eliminate the existence of the 8-coordinate cis-isomer $\mathbf{1}^{\prime \prime}$ as well as the 10-coordinate trans-isomer 2", because the corresponding structures have not been detected by the X-ray structural analysis of $\mathbf{1}$ and $\mathbf{2}$. If this is the case, the fluxional behavior in solution is best explained as a rapid exchange between the pairs of isomers derived from the bicapped octahedral and the bicapped square antiprismatic
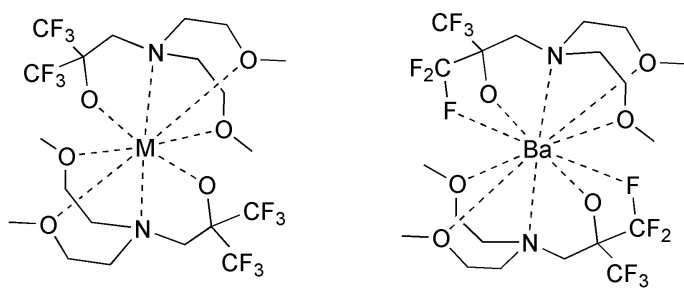

$M=\operatorname{Sr}(1) ; M=B a(2 ")$

(2')

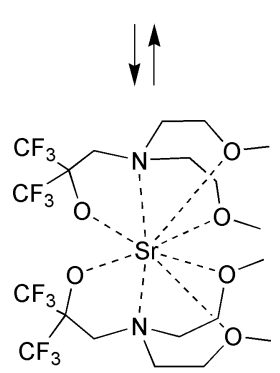

(1')

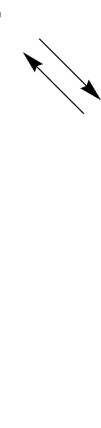

geometry, i.e. the $\mathbf{1}$ and $\mathbf{1}^{\prime}$ pair and the $\mathbf{2}$ and $\mathbf{2}^{\prime}$ pair, respectively.

Although we cannot rule out either possibility based on the present ${ }^{19} \mathrm{~F}$ NMR evidence, it is important to note that the coordinated $\mathrm{CF}_{3}$ group of the amak ligands in the 10coordinate barium complex 2 would exhibit a fast threefold rotation about its $\mathrm{C}-\mathrm{CF}_{3}$ axis. This rotational motion must be accompanied by a concurrent breaking and reforming of the $\mathrm{M} \cdot \mathrm{F}$. dative interactions as well as rapid interchange between the coordinated and the non-coordinated $\mathrm{CF}_{3}$ substituents, as only one ${ }^{19} \mathrm{~F}$ NMR signal was observed at room temperature, irrespective of the presence of two chemically distinctive $\mathrm{CF}_{3}$ substituents in the solid-state. The fluxionality is independent of the polarity of the solvent system and this is revealed by the result that addition of excess THF to the non-polar $\mathrm{CD}_{2} \mathrm{Cl}_{2}$ solution causes no change in the VT ${ }^{19} \mathrm{~F}$ NMR spectral pattern.

Moreover, for both complexes $\mathbf{1}$ and 2, a relatively weak signal at $\delta-77.6$ was clearly observed in the ${ }^{19} \mathrm{~F}$ NMR spectra recorded at lower temperatures. This signal cannot be removed by any means and has been assigned to the dissociated aminoalcohol ligand (amak)H, which may be produced from inadvertent hydrolysis during preparation of the NMR samples. Interestingly, this signal disappeared upon raising the temperature to $295 \mathrm{~K}$, implying that a rapid intermolecular exchange with the ligated aminoalkoxide may be occurring under these conditions.

After completing the spectroscopic identification, the physical properties important to CVD studies were established. It showed that both complexes underwent sublimation without notable decomposition at $150^{\circ} \mathrm{C}$ under a pressure of 200 mTorr overnight, as samples obtained before and after sublimation exhibited identical spectroscopic and physical characteristics. The thermal behaviors were also investigated by TG analysis under $\mathrm{O}_{2}$ at $1 \mathrm{~atm}$ and a rapid loss of weight was observed at about $220^{\circ} \mathrm{C}$ due to a combination of sample sublimation and decomposition, giving an off-white residue upon increasing the temperature to $500{ }^{\circ} \mathrm{C}$ (1: $14.6 \mathrm{wt} \%$, 2: $30.8 \mathrm{wt} \%$ ). Powder XRD analysis confirmed that these solid residues contain mainly polycrystalline metal fluorides $\mathrm{SrF}_{2}$ and $\mathrm{BaF}_{2}$, giving a first indication that these complexes were suitable CVD precursors.

Preliminary experiments were carried out to probe the possibility of depositing fluoride thin films from aminoalkoxide complexes $\mathbf{1}$ and 2; most of the previous reports utilized the fluorinated $\beta$-diketonate complexes as the CVD source reagents. ${ }^{2,19}$ Our data indicated that the $\mathrm{BaF}_{2}$ thin film can be deposited on both Pyrex glass and $\mathrm{Si}(100)$ substrate at $350^{\circ} \mathrm{C}$, 


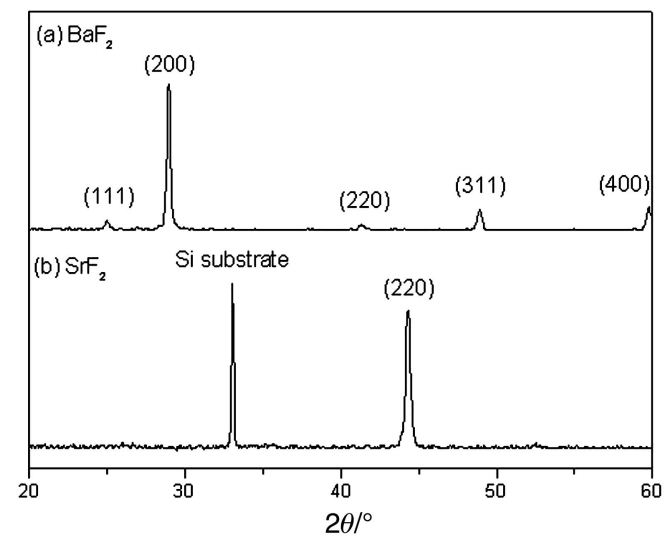

Fig. 4 The XRD patterns for the thin film samples obtained from CVD experiments using complexes $\mathbf{2}$ and $\mathbf{1}$ as the source reagents: (a) $\mathrm{BaF}_{2}$ and (b) $\mathrm{SrF}_{2}$.

using 2 as source reagent under a carrier gas of Ar. The XRD measurement showed formation of a polycrystalline texture on the Pyrex glass substrate, giving a preferential orientation along the (200) planes on the Si(100) surface (Fig. 4). The formation of such highly ordered thin films is not uncommon as it has been observed in CVD experiments using the $\mathrm{Ba}(\mathrm{hfac})_{2}$ (tetraglyme) adduct ( $\mathrm{hfac}=1,1,1,5,5,5$-hexafluoropentane-2,4dionate).$^{20}$ Upon switching to complex $1, \mathrm{SrF}_{2}$ thin films with a preferred (220) orientation on a $\mathrm{Si}(100)$ surface was obtained using a $1: 1$ mixture of $\mathrm{Ar}$ and $\mathrm{O}_{2}$ as carrier gas.

In summary, our results show that the designed synthesis of alkaline-earth metal fluoroalkoxide complexes has been achieved, for which the bonding mode of the fluoroalkoxide ligands in the solid state is determined by the nature of the central metal cation. All $\mathrm{O}$ and $\mathrm{N}$ donor atoms on the side chain are coordinated to the metal cation and in the case of the barium complex 2 two additional fluorine contacts are clearly observed. The weak basicity of the alkoxide oxygen and the coordinative unsaturation of the larger barium center make these fluorine dative contacts energetically favorable. Moreover, of particular interest is the formation of two rapidly interconvertible isomers in solution, which may be attributed to the intramolecular cis-trans isomerization or the transformation between the 8-coordinate bicapped octahedral and the 10coordinate bicapped square antiprismatic geometry. The relatively high volatility of these two complexes makes them optimum CVD source reagents for growing fluoride thin-films. Accordingly, preservation of a certain degree of intramolecular $\mathrm{M} \cdots \mathrm{F}$ dative bonding is possible during precursor evaporation and vapor transport, which in turn can be used to account for the rapid formation of the metal fluorides.

\section{Acknowledgements}

We thank the National Science Council, Taiwan, Republic of China for funding (Grant No. NSC 89-2113-M-007-034).

\section{References}

1 (a) D. G. Gilliland, M. L. Hitchman, S. C. Thompson and D. J. Cole-Hamilton, J. Phys. III, 1992, 2, 1381; (b) M. Tiitta and L. Niinistö, Chem. Vap. Deposition, 1997, 3, 167; (c) J. A. P. Nash, J. C. Barnes, D. J. Cole-Hamilton, B. C. Richards, S. L. Cook and M. L. Hitchman, Adv. Mater. Opt. Electron., 1995, 5, 1; (d) A. C. Jones, Chem. Vap. Deposition, 1998, 4, 169; (e) W. Clegg, S. J. Coles, E. K. Cope and F. S. Mair, Angew. Chem., Int. Ed., 1998, 37, 796.

2 (a) A. P. Purdy, A. D. Berry, R. T. Holm, M. Fatemi and D. K. Gaskill, Inorg. Chem., 1989, 28, 2799; (b) H. Sato and S. Sugawara, Inorg. Chem., 1993, 32, 1941; (c) O. Poncelet, J. Guilment and D. Martin, J. Sol-Gel Sci. Technol., 1998, 13, 129.
3 (a) S. Sinharoy, Thin Solid Films, 1990, 187, 231; (b) E. Daran, L. E. Bausa, A. Muñoz-Yagüe and C. Fontaine, Appl. Phys. Lett., 1993, 62, 2616; (c) H. Sato, Jpn. J. Appl. Phys., 1994, 33, L368.

4 (a) W. A. Wojtczak, P. F. Fleig and M. J. Hampden-Smith, $A d v$. Organomet. Chem., 1996, 40, 215; (b) D. C. Bradley, Polyhedron, 1994, 13, 1111; (c) H. A. Meinema, K. Timmer, H. L. Linden and C. I. M. A. Spee, Mater. Res. Soc. Symp. Proc., 1994, 335, 193; (d) T. J. Marks, Pure Appl. Chem., 1995, 67, 313; (e) J. Brooks, H. O. Davies, T. J. Leedham, A. C. Jones and A. Steiner, Chem. Vap. Deposition, 2000, 6, 66.

5 (a) D. C. Bradley, M. Hasan, M. B. Hursthouse, M. Motevalli, O. F. Z. Khan, R. G. Pritchard and J. O. Williams, J. Chem. Soc., Chem. Commun., 1992, 575; (b) S. R. Drake, M. B. Hursthouse, K. M. A. Malik and D. J. Otway, J. Chem. Soc., Dalton Trans., 1993, 2883; (c) J. Brooks, H. O. Davies, T. J. Leedham, A. C. Jones and A. Steiner, Chem. Vap. Deposition, 2000, 6, 66.

6 (a) K. G. Caulton, M. H. Chisholm, S. R. Drake and J. C. Huffmann, J. Chem. Soc., Chem. Commun., 1990, 1498; (b) A. P. Purdy, C. F. George and J. H. Callahan, Inorg. Chem., 1991, 30, 2812; (c) B. Borup, J. A. Samuels, W. E. Streib and K. G. Caulton, Inorg. Chem., 1994, 33, 994; (d) H. Vincent, F. Labrize and L. G. Hubert-Pfalzgraf, Polyhedron, 1994, 13, 3323.

7 (a) W. S. Rees, Jr., M. W. Carris and W. Hesse, Inorg. Chem., 1991, 30, 4479; (b) G. Rossetto, A. Polo, F. Benetollo, M. Porchia and P. Zanella, Polyhedron, 1992, 11, 979; (c) W. A. Wojtczak, M. J. Hampden-Smith and E. N. Duesler, Inorg. Chem., 1998, 37, 1781; (d) K. G. Caulton, M. H. Chisholm, S. R. Drake and K. Folting, Inorg. Chem., 1991, 30, 1500.

8 (a) J. A. T. Norman and G. P. Pez, J. Chem. Soc., Chem. Commun., 1991, 971; (b) S. R. Drake, M. B. Hursthouse, K. M. A. Malik and S. A. S. Miller, J. Chem. Soc., Chem. Commun., 1993, 478; (c) S. R. Drake, M. B. Hursthouse, K. M. A. Malik, S. A. S. Miller and D. J. Otway, Inorg. Chem., 1993, 32, 4464; (d) J. R. Babcock, D. D. Benson, A. Wang, N. L. Edleman, J. A. Belot, M. V. Metz and T. J. Marks, Chem. Vap. Deposition, 2000, 6, 180.

9 (a) W. A. Herrmann, N. W. Huber and O. Runte, Angew. Chem., Int. Ed. Engl., 1995, 34, 2187; (b) W. A. Herrmann and N. W. Huber, Chem. Ber., 1994, 127, 821.

10 W. S. Rees, Jr. and D. A. Moreno, J. Chem. Soc., Chem. Commun., 1991, 1759

11 (a) A. M. Bahl, S. Krishnaswamy, N. G. Massand, D. J. Burkey and T. P. Hanusa, Inorg. Chem., 1997, 36, 5413; (b) L. G. HubertPfalzgraf, F. Labrize, C. Bois and J. Vaissermann, Polyhedron, 1994, 13, 2163; (c) D. L. Schulz, B. J. Hinds, D. A. Neumayer, C. L. Stern and T. J. Marks, Chem. Mater., 1993, 5, 1605; (d) J. S. Matthews, O. Just, B. Obi-Johnson and W. S. Rees, Jr., Chem. Vap. Deposition, 2000, 6, 129.

12 J. E. Huheey, E. A. Keiter and R. L. Keiter, Inorganic Chemistry: Principles of Structure and Reactivity, Harper Collins College Publishers, New York, 4th edn., 1993, p. 116.

13 (a) G. M. Sheldrick, SHELXTL, version 5.10, Siemens Analytical X-ray Instruments Inc., Madison, WI, 1998; (b) SMART and SAINT, Siemens Analytical X-ray Instruments Inc., Madison, WI, 1995; (c) G. M. Sheldrick, SADABS, University of Göttingen, Germany, 1996; (d) C. K. Johnson, ORTEP, Report no. ORNL5138, Oak Ridge National Laboratory, Oak Ridge, TN, 1976.

14 I.-S. Chang and C. J. Willis, Can. J. Chem., 1977, 55, 2465.

15 B. Borup, W. E. Streib and K. G. Caulton, Inorg. Chem., 1997, 36, 5058.

16 P.-F. Hsu, Y. Chi, T.-W. Lin, C.-S. Liu, A. J. Carty and S.-M. Peng, Chem. Vap. Deposition, 2001, 7, 28

17 (a) J. A. Samuels, E. B. Lobkovsky, W. E. Streib, K. Folting, J. C. Hoffman, J. W. Zwanziger and K. G. Caulton, J. Am. Chem. Soc., 1993, 115, 5093; (b) A. P. Purdy and C. F. George, ACS Symp. Ser., 1994, 555, 405; (c) Y. Chi, S. Ranjan, P.-W. Chung, C.-S. Liu, S.-M. Peng and G.-H. Lee, J. Chem. Soc., Dalton Trans., 2000, 343; $(d)$ L. G. Hubert-Pfalzgraf, Coord. Chem. Rev., 1998, 178-180, 967; (e) F. Labrize, L. G. Hubert-Pfalzgraf, J. C. Daran and S. Halut, J. Chem. Soc., Chem. Commun., 1993, 1556; $(f)$ A. P. Purdy and C. F. George, Inorg. Chem., 1991, 30, 1970; (g) A. Drozov, A. Pozhitkov, S. Troyanov and A. Pisarevsky, Polyhedron, 1996, 15, 1731 .

18 D. A. Neumayer, J. A. Belot, R. L. Feezel, C. Reedy, C. L. Stern, T. J. Marks, L. M. Liable-Sands and A. L. Rheingold, Inorg. Chem., $1998,37,5625$.

19 M. L. Hitchman, S. H. Shamlian, D. D. Gilliland, D. J. Cole-Hamilton, J. A. P. Nash, S. C. Thompson and S. L. Cook, J. Mater. Chem., 1995, 5, 47.

20 G. Malandrino, F. Castelli and I. L. Fragala, Inorg. Chim. Acta, 1994, 224, 203. 